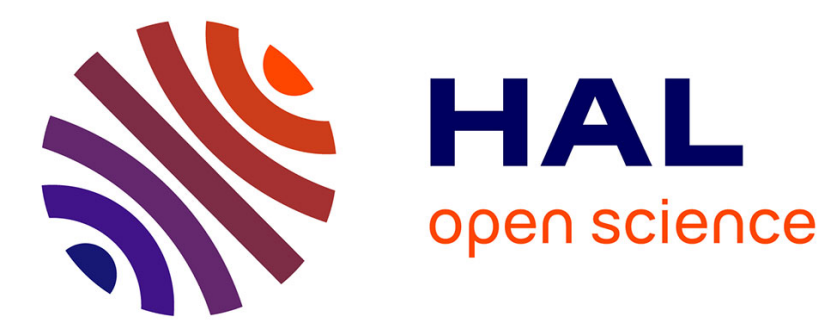

\title{
Disentangling dam impacts in river networks.
}

K. van Looy, T. Tormos, Y. Souchon

\section{To cite this version:}

K. van Looy, T. Tormos, Y. Souchon. Disentangling dam impacts in river networks.. Ecological Indicators, 2014, 37, p. 10 - p. 20. 10.1016/j.ecolind.2013.10.006 . hal-00916423

\section{HAL Id: hal-00916423 \\ https://hal.science/hal-00916423}

Submitted on 10 Dec 2013

HAL is a multi-disciplinary open access archive for the deposit and dissemination of scientific research documents, whether they are published or not. The documents may come from teaching and research institutions in France or abroad, or from public or private research centers.
L'archive ouverte pluridisciplinaire HAL, est destinée au dépôt et à la diffusion de documents scientifiques de niveau recherche, publiés ou non, émanant des établissements d'enseignement et de recherche français ou étrangers, des laboratoires publics ou privés. 
1 Disentangling dam impacts in river networks

2 Kris Van Looy, Thierry Tormos and Yves Souchon

\section{Abstract}

Irstea Lyon - UR MALY - River hydro-ecology research unit Onema-Irstea

5 rue de la Doua CS70077

69100 VILLEURBANNE Cedex

+33(0)472208941

Kris.van-looy@irstea.fr

Damming is one of the most widespread impairments of river systems around the world. The formulation of scientifically justified guidelines for restoration and remediation of impairments requires better understanding of the relationships between alteration and stream condition. The present study examines relationships between the presence and density of dams and biological metrics of river health in the context of a variety of environmental drivers over the Loire river basin. We hypothesized that dam density measured at supra-reach level would show more significantinfluence on river health than the local level density, and further that the impact of dams is best estimated with measures for the functional traits of biotic assemblages. An extensive dataset of fish (169 sites) and invertebrate (211 sites) communities in the Loire river basin,described with metrics of density of ecological guilds, taxonomic richness and life history traits,and coupled with reachhydromorphology and catchment characteristics was constructed.Generalized linear modellingwas performed in order to quantify dam impact and investigate the importance of regional- and local-scale measures of dam density to the structure of biotic communities. The analysis showed that community structure at the basin scale responded significant to dam presence and confirmed that the strongest relationships were observed for specific functional trait-based metrics. For the macroinvertebrates the observed impact counts up to $25 \%$ of the variance in the trait-based quality indices, whereas for fish communities the dam density only explains up to $12 \%$. Macroinvertebrate responses were stronger at higher scale level, and especially the upstream context explained on its own $70 \%$ of the observed impairment. For fish communities, the local context prevails and explained up to $70 \%$ of the dam impact. These results can be explained by the biotic processes ruling community assembly in the specific groups, passive dispersal for the invertebrates and migrations between habitats for fish. The geographic context furthermore explains the differentiation in these responses, reflecting the metacommunity structure of invertebrate assembly over the river basin. We conclude that for upstream parts of the river basin, locally based management actions can be successful in restoring biotic integrity, whereas more downstream, dam removal actions require more integrated measures at regional rather than local scale.

\section{Highlights}

- Dam density is proposed as a multi-scale indicator distinguishing local and network scale impact.

- Responses in macroinvertebrate and fish communities are strongest for functional trait metrics

- Macroinvertebrate communities respond strongest to upstream dam density whereas for fish the local context prevails. Invertebrate assembly and responses reflect metacommunity structure. Upstream-downstream contexts and responses differ and demand for different restoration strategies.

Keywords: dam density indicators; biotic integrity; macroinvertebrates; fish; trait metrics. 


\section{Introduction}

Large-scale and even globally programs are launched targeting the rehabilitation of river systems and water allocation for a sustainable provision of services of freshwater ecosystems (Vörösmarty, 2010). The great majority of river systems of the world are subjected to flow regulation and impoundment; over half of the world's large river systems are affected by dams (Nilsson et al., 2005), and, for example, Graf (2001) estimates that only $2 \%$ of rivers in the United States remain unaffected by dams. Reported impacts of dams concern a degradation of habitat and a fragmentation of populations, with losses of productivity, reduced distribution ranges and changes documented for fish community composition (Santucci et al., 2005 ; Catalano et al., 2007 ; Slawski et al., 2008), as well as for aquatic invertebrate communities (Brittain and Saltveit, 1989; Watters, 1996; Cortes et al., 1998; Benstead et al., 1999; Conception \& Nelson, 1999; Marchant and Hehir, 2002; Stanley et al., 2002; Blakely et al., 2006).

Recently, questions on the opportunity of dam removal and the ecological benefits of such restoration measures arise, but for specific contexts, the general rationale for restoring natural features often seems to get lost, and not only due to uses conflicts (Donnelly et al., 2002; Lejon et al., 2009). Often there is a local attachment to existing landscape features and scenery, but more importantly river managers encounter resistance of conservationist and fisheries stakeholders that question the potential gains and stress the risks of species loss.Nevertheless there is general agreement to the injurious character of human alterations and to the application of a reference approach (Hansen and Hayes, 2012). But especially the strong emphasis on the river's corridor functioning and the impact of obstacles to ecological networks, demands for dam removal.As a result, there's need for advanced assessments of the role and effects of dams within river networks to support strategies for mitigating ecohydrological and socioeconomic costs, and recently important efforts are made globally to the inventory of reservoirs and dams (Lehneret al., 2011), or to evaluate their impact on river ecology (Petts,1984; Acreman and Ferguson, 2010). In France and Western Europe in general, the high degree of flow regulation and the governmental initiatives to address environmental problems under the Water Framework Directive provide the need and impetus for environmental water allocations and the need to monitor and assess the ecological effects.

In literature, impact of dams is generally examined on the local context, and very often, no significant negative effect to local biotic communities can be attributed (Pohlon et al., 2007). From a long year study to the effects of an impoundment (Maynard and Lane, 2012) observed even an increase in species richness, which they attributed to the buffering effects to peak velocity and low flows. Recent studies, dealing with the question at a more comprehensive level, include the entire drainage basin because of the importance of tributary-main stem and upstream-downstream connections in a drainage basin (Wohl, 2012). The basin context of dam impacts has been elucidated for sediment provision, water allocation, fish diversity and food security (Fitzhugh, 2011). Of course this impact is most clear for diadromous species. But, for example, Ziv et al. (2012) demonstrate the damaging impact on resident fish populations at river basin scale revealing strong impacts of upstream tributary dams on overall sustainability of fish populations. With the individual dam's geographic setting, aspects of the position and accumulation of dam impacts in the river network are a key issue in assessment (Poff and Hart, 2002). Therefore the entire drainage must be included in such studies in paying a particular attention on the geographical context because the response to damming may also be expected to differ between small upstream streams and large alluvial rivers (Nilsson et al., 2005).

From a metacommunity perspective, a loss of connectivity can cause local extirpations due to changes in environmental conditions (Chase and Leibold, 2002) or to a lack of re-colonization sources (Mouquet andLoreau, 2002). Knowledge on the metacommunity structure and the nature of the impairments, whether the disconnection or habitat degradation impact dominates, can generate important information to determine conservation and restoration actions. Trait-based bio-assessment may in this respect have several advantages to enhance causal diagnosis over taxonomically based methods (Archaimbault et al., 2010). These include providing mechanistic linkages of biotic responses to environmental conditions, and consistent descriptors or metrics across broad spatial scales (Culp et al., 2011). 
In this paper, two hypotheses are put forward for these questions to biotic community changes caused by dams with regard to geography and network constellation. Firstly, the impact of dams on the biotic communities in the river network is supposed to count more at the regional than just the local scale.And if so, does this mean that the disconnection impact is stronger than the habitat degradation impact? The second hypothesis deals with the specificity of biotic groups; different responses are expected for different groups. Based on the higher mobility of fish compared to invertebrates, impact on fish is most expected for connectivity and at a larger scale, whereas for invertebrate communities local habitat degradation should prevail. So, in addition to this second hypothesis questions arise for the geographic aspect.Does a general highland-lowland distinction control the impacts; in highlands mostly measurable in habitat degradation, whereas for lowland regions more connectivity aspects are involved?

To deal with the hypotheses, an analysis is presented on a representative part of the French river network, for the largest river basin of the Loire River that is governed and surveyed by a single authority, offering a homogeneous set of data for both dams and biotic surveys in the network. Moreover, as dams and weirs on the French rivers are present for a long-time, the consequences of disconnection can be assessed without risk of delayed response; if it takes time for the consequences of damming to impact on communities (Ormerod et al., 2010), by now these consequences should be in place.

\section{Material and methods}

\subsection{Study area and datasets}

The Loire river basin covers a total area of $155,000 \mathrm{~km}^{2}$ or $22 \%$ of French territory, which makes it one of the largest in Western Europe (see Figure 1). The Loire is more than 1,000 km in length and has its source at 1,048 $\mathrm{m}$ altitude. With its preserved free-flowing character the main river has an exceptional conservation value. The basin offers a stronghold for anadromous migratory fish species for the European mainland, with a unique relic Atlantic salmon population. The surveyed river network consists of $17000 \mathrm{~km}$ river length, divided in 4930 river segments homogeneous in geomorphological characteristics. The splitting into these geo-morphological units is based on a semiautomatic sectioning that distinguishes changes in geological entities, channel form, sinuosity and valley floor width (Chandesris et al., 2008). Resulting river segments range from $1 \mathrm{~km}$ on average for small streams, up to $20 \mathrm{~km}$ on average for large rivers. The gradation in length conforms to the increase in size of rivers and of their functional mesohabitat entities. This spatial framework allows studying dam impacts (disconnection and impoundments) over the entire basin independently of geomorphological gradients and variation.

This hierarchical spatial framework was constructed for the entire French river network and is a product of thenational hydromorphology audit system, SYRAH (Chandesris et al., 2008). This database also provides, for each of these river segments, information on both natural and anthropogenic hydromorphological pressure variables at two spatial scales(the upstream catchment and the local river segment), using suitable spatial data available over the national territory. At the upstream catchment scale land cover information was derived from the CORINE land cover database (drawn from satellite imagery at a scale of 1: 100 000, with a minimum polygon size of 25 ha, http://www.eea.europa.eu/publications/COR0-landcover). At local river segment scale, hydromorphological pressures were derived from the French geo-database with metric precision (IGN, RGE® database, http://www.ign.fr/institut/activites/referentiel-a-grande-echelle). Moreover, it informs on the risk alterations of hydromorphological processes. The hydro-morphological variables and alteration risk information collected in this study are summarized in Table 1.

Then, Information on dams was gathered over the Loire basin from the French obstacles inventory (ROE® database, finalized version November 2011, http://www.onema.fr/REFERENTIEL-DESOBSTACLES-A-L), that is produced by the national agency for water and aquatic environments (Onema) andgives reliable information on the localization of dams.More than 5500 dams are present in the surveyed network according to the ROE® database, with a relative absence of dams on the downstream part of the Loire and its main tributary the Allier (see Figure 1) 
And finally, biological data was retrieved from the French national monitoring network which gives information on of the water quality on a stabilised set of 1649 stations. The spatial distribution of the monitoring stations tries to achieve a type-selective and spatial coverage for a general quality assessment. The local sampling site selection is intended to be representative for the overall biotic quality of the specific river reach. We selected a set of stations that correspond to a spatial and typespecific distribution at the scale of theLoire River basin, and we applied a neighbourhood criterion to reduce spatial autocorrelation (nearest station in the network were eliminated).. This resulted in a network consisting of 211 invertebrate and 169 fish stations evenly distributed over the hydroecoregions and river types in the river basin.

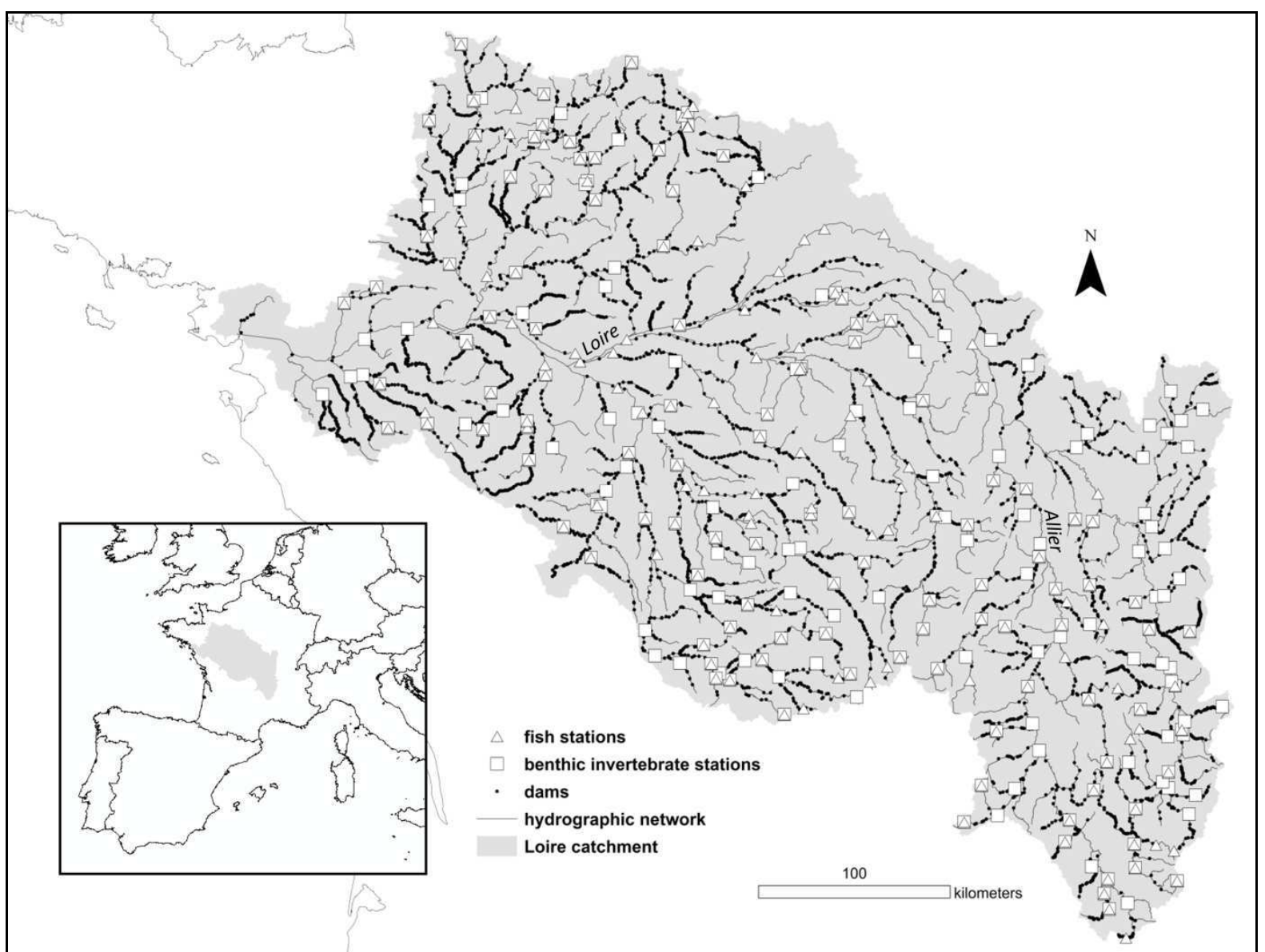

Figure 1. Localization of the Loire Basin with dams of national obstacle inventory (ROE®) and fish and benthic invertebrate sampling stations of the national monitoring network.

Table 1: hydro-morphological variables and alteration risk information from SYRAH database

\begin{tabular}{llll}
\hline Scale & $\begin{array}{c}\text { hydro-morphological } \\
\text { variable type }\end{array}$ & Name & Description \\
\hline $\begin{array}{c}\text { upstream } \\
\text { catchment }\end{array}$ & pressure & intensive agriculture & $\begin{array}{l}\text { percentage cover of urban land use class in CORINE land cover } \\
\text { data of the upstream catchment } \\
\text { percentage cover of intensive agricultural CORINE land cover } \\
\text { classes of the upstream catchment } \\
\text { percentage cover of near-natural CORINE land cover classes data } \\
\text { of the upstream catchment }\end{array}$ \\
\hline $\begin{array}{c}\text { local river } \\
\text { segment }\end{array}$ & neography & altitude & elevation at downstream point of river segments \\
& river slope & slope of the river bed over the segment \\
& valleyslope & Discharge & $\begin{array}{l}\text { valley slope perpendicular to the river } \\
\text { mean annual discharge for gauging station or model prediction at } \\
\text { river segment level }\end{array}$
\end{tabular}


177

178

179

180

181

182

183

184

185

186

187

188

189

190

191

192

\begin{tabular}{cll} 
& Sinuosity & sinuosity of the river bed over the segment \\
pressure & channelstraightening & $\begin{array}{l}\text { percentage of straight reaches over the segment, weighed by river } \\
\text { type } \\
\text { percentage cover of infrastructure over riparian buffer of three } \\
\text { river widths of the segment } \\
\text { percentage cover of urbanisation for the } 100 \mathrm{~m} \text { riparian buffer of } \\
\text { the river segment } \\
\text { percentage cover of forest patches for the } 30 \mathrm{~m} \text { riparian buffer of } \\
\text { the river segment }\end{array}$ \\
& riparian urbanisation & $\begin{array}{l}\text { bedsubstrate alteration risk based on local re-dimensioning and } \\
\text { upstream sediment blocking } \\
\text { alteration risk to hydrological regime, based on upstream } \\
\text { abstractions and reservoirs }\end{array}$ \\
\hline
\end{tabular}

\subsection{Construction of dam impact indicators}

Indicators for dam impact in the river network at three distinct scale levels were developed for the appraisal of the distinct effects of dam presence to biota and computed for each biological station. At the local level, four indicators were designed. First, the elementary number of dams (dam\#) per river segment, it is defined as follows:

$$
\text { (1) } \quad d a m \#=N b_{\text {dams }}
$$

where $\mathrm{Nb}_{\mathrm{dams}}$ is the number of dams geo-localized by the ROE® database on the river segment.

Second, the normalized density of dams which corresponds to the number of dams per km and ranges between 0 and 1 . It is given by:

$$
\operatorname{Ddam\# }{ }_{\mathrm{L}}=\frac{\operatorname{dam\# }{ }_{\mathrm{L}}-{ }_{\max } \operatorname{dam}_{\mathrm{L}}}{\max }
$$

with:

$$
\operatorname{dam\# }_{\mathrm{L}}=\frac{\sqrt{\operatorname{dam\# }}}{L_{\mathrm{rs}}}
$$

where $L_{r s}$ is the length of the river segment in $\mathrm{km}$ and ${ }_{\max } d a m \#_{\mathrm{L}}$ the maximum dam density observed over the entire surveyed network.

Third a slope-weighed measure for the normalizeddam density:

$$
\operatorname{Ddam\# }_{\mathrm{LS}}=\frac{\operatorname{Ddam\# }_{\mathrm{L}}}{\sqrt{S_{r s}}}
$$

where $S_{r s}$ the river segment's slope in percentage. This measure diminishes the influence of the geographic setting to the dam impact: under lower slopes the dam creates larger impounded sections. This slope weighing gives a reliable estimate to the impounded fraction in the absence of complete data on the height of dams. For the analysis, it offers the opportunity to distinguish between predominance of habitat degradation impact by impoundment and the disconnection impact measured by the obstacle density.

Fourth thenetwork distance to the nearest downstream dam, a measure that is commonly described in literature(Cumming, 2004; Musil et al., 2012), is defined as follows:

(4) ${ }_{\text {near }}$ dam $=d_{\text {curv }}$ 
whered $_{\text {curv }}$ is the network (curvilinear) distance between the biological station and the nearest downstream dam. This distance is measured using dynamic segmentation techniques available in ESRI software.

At the regional scale, a series of true network indicators for dam density are constructed with a riveradapted version of the Integral Indexof Connectivity (IIC) concept designed in (Pascual-Hortal and Saura, 2006, Pascual-Hortal and Saura, 2008), using the $d I I C$ metric. This metricaddresses the contribution of an individual node to connectivity in the network according to a given descriptive variable.

In our river network adaptation, network nodes correspond to river segments. For the connected dendritic structure of the river network, a constrained connectivity analysis can be proposed, for which each segment is regarded in relation to its surrounding segments with a restriction in distance. In such network, $d_{\text {net } i j}$ corresponds to the topological distance between any $i$ and $j$ river segment. With $i \in[1 ; N]$ where $N$ is the total number of river segments in the river network; and $j \in\left\lfloor 1 ; N_{(i)}\right\rfloor$ where $N_{(i)}$ is the total number of neighbouring river segments to segment $i$ within a specified topological distance inferior to $d_{n e t} x$. This maximum topological distance, defined by the operator, is introduced in order to build $d I I C$ metrics across different neighbour networks. When $i=j$ then $d_{n e t i j}=0$, see Figure 2A for an illustration of spatial configuration of the river segment network and topological distance.

From this spatial configuration $d I I C$ for a $X$ river segment is given by:

(5) $\operatorname{dIIC}_{(X)}=100 \frac{I I C_{(1 \leq i \leq N)}-I I C_{(1 \leq i \leq N, i \neq X)}}{I I C_{(1 \leq i \leq N)}}$

with

$I I C_{\left(x_{1} \leq i \leq x_{2}\right)}=\sum_{i=x_{1}}^{x_{2}} \frac{\sum_{j=1}^{N_{(i)}} \frac{a_{i} \cdot a_{j}}{1+d_{n e t i j}}}{L_{N_{(i)}}}$

where $x_{1}$ and $x_{2} \in[1 ; N], a$ is the descriptive variable - a segment-scale dam density measure here for the river segment, $L_{N_{(i)}}$ the length of the considered neighbouring network. IIC ponders the descriptive variable according to the topological distance: the higher the topological distance, the lower the weight attributed to the descriptive variable in its calculation. It ranges from 0 to 1 and increases with higher connectivity, which depends on both the quality (according to the descriptive variable) and the density (branchiness) of the river network.

dIIC is the percentage of index value loss when the river segment is removed from the overall index calculation .ThedIIC measures the contribution of the individual segment to the overall network connectivity (Pascual-Hortal and Saura 2008). As the dIIC is a quality measure, the inverse dam density of the segments was used in its calculation (and thus shows an opposite sign in the analyses compared to the other measures). Seperate $d I I C$ values were calculated for the inverse dam density $\operatorname{Ddam}_{\mathrm{L}}$ and the slope weighed dam densityDdam\# ${ }_{\mathrm{LS}}$ in order to evaluate the dominance of impoundment impact (if weighed measure prevails) over disconnection impact (measured with dam density). Furthermore, thedIICwas calculated for different distances of network neighbours: with 5 neighbouring segments $\left(d_{n e t} x=5, \mathrm{dIIC}_{5}\right)$ and witha more regional network, 10 neighbouring segments $\left(d_{n e t} x=10, \mathrm{dIIC}_{10}\right)$. The $d I I C$ values range from 0 to $100(d I I C=0$ in the hypothetical case that the 
given river segment does not contribute to the network). An illustration of $d I I C$ values forDdam\# $\#_{\mathrm{L}}$ is presented in Figure 3for each river segment of the Loire Basin.

The neighbourhood matrix for the upstream-downstream connections between river segments in the networkis constructed with python using the network topology format provided by ESRI software. The ConeforSensinode 2.2 software (Saura and Torné, 2009) was used to calculate the $d I I C$ values.

Finally, at the highest scale level, an indicator for the accumulation of dams in the upstream river network is calculated as the averaged segment dam density for the entire upstream catchment. For this measure, all the segment's dam densities have the same weight (in contrast to the $d I I C$ measure), and the measure gives a relative measure of dam density for the entire upstream basin to the local site. At this scale, only the slope weighed dam density $\left(\right.$ Ddam $\left._{L S}\right)$ was aggregated as follows:

(6) cumulu $_{\operatorname{dam} \#_{\mathrm{LS}}}=\frac{\sum_{i=1}^{N_{u}} \operatorname{dam}_{\mathrm{LS}_{(i)}}}{N_{u}}$

where dam\# $\#_{\mathrm{LS}(i)}$ is the $\operatorname{dam}_{\mathrm{LS}}$ for the river segment $i$ and $N_{u}$ the number of upstream river segment. This measure corresponds to the average of $d a m \#_{L S}$ over the upstream catchment. Upstream river segment are selected using the network topology format provided by ESRI software.

Table 2 summarizes the description of each dam impact indicator and Figure 2B presents the spatial footprint of dam density indicators on the river network at the different scales.

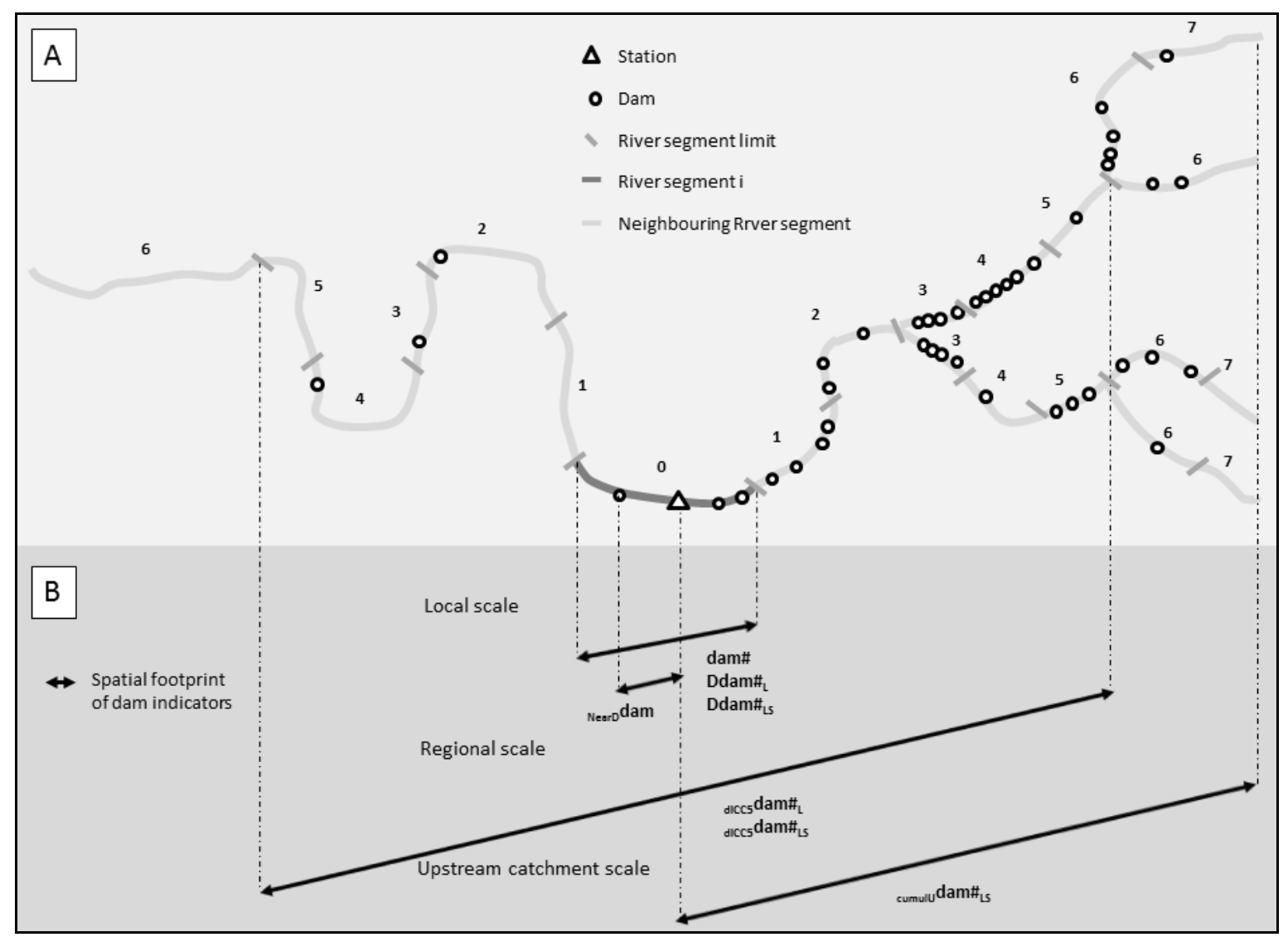

Figure 2.Spatial configuration of river network for building dam indicators based on the geomorphological river segments and schematisation of dam indicators spatial footprint for the different scales (local, regional and upstream catchment scale). Numbers are relative to the topological distance to the river segmenti. See Table 2 for the labels ofindicators. 
Table 2: Dam impact indicators computed for each biological station

\begin{tabular}{|c|c|c|}
\hline Scale & Label & Description \\
\hline \multirow[t]{4}{*}{ local river segment } & dam\# & number of weirs/damsper segment \\
\hline & NearDdam & Nearest network distance to a downstream dam \\
\hline & Ddams $\#_{\mathrm{L}}$ & number of weirs/damsper segment, divided by river length \\
\hline & Ddams\# $\#_{\mathrm{LP}}$ & $\begin{array}{l}\text { weighed dam density for slope of river segment more related to impoundment } \\
\text { impact (under lower slopes the dam creates larger impounded sections) }\end{array}$ \\
\hline \multirow{4}{*}{ regional network } & $\mathrm{dIIC}_{5} \mathrm{dams}_{\mathrm{L}}$ & $\begin{array}{l}\text { Individual segment's contribution to the overall network connectivity according } \\
\text { todam density for } 5 \text { neighboring river segments }\end{array}$ \\
\hline & $\mathrm{dIIC}_{5} \mathrm{dams}_{\mathrm{LP}}$ & $\begin{array}{l}\text { Individual segment's contribution to the overall network connectivity according } \\
\text { to slope weighed dam density for } 5 \text { neighboring river segments }\end{array}$ \\
\hline & $\mathrm{dIIC}_{10}$ dams $_{\mathrm{L}}$ & $\begin{array}{l}\text { Individual segment's contribution to the overall network connectivity according } \\
\text { todam density for } 10 \text { neighboring river segments }\end{array}$ \\
\hline & $\mathrm{dIIC}_{10} \mathrm{dams}_{\mathrm{LP}}$ & $\begin{array}{l}\text { Individual segment's contribution to the overall network connectivity according } \\
\text { toweighed dam density for } 5 \text { neighboring river segments }\end{array}$ \\
\hline upstream catchment & cumuludam\# $\#_{L P}$ & Averaged slope weighed dam density of upstream river segments \\
\hline
\end{tabular}

\subsection{Assessing biotic integrity}

To evaluate the general ecological quality, aspects of taxonomic richness and abundance for the biotic communities are investigated. For our analysis we consider both the multi-metric general biotic integrity indicators and the underlying metrics (see Table 3). All the used metrics are constructed in the same way for a type-specific evaluation of community composition. Both the overall multi-metric biotic integrity indices as the constituting taxonomic or life history trait-based metrics are conceived as distance to a type-specific reference condition (for construction, see Mondy et al.,2012). This application of reference-based metrics allows removing the principal problems of spatial structuring and autocorrelation of the data, as with these integrity metrics the natural community richness and composition gradients are eliminated. With the construction of the site-specific and hierarchic spatial indicators for dam density, and the type-specific distribution of the biological monitoring sites, the problem of spatial autocorrelation is largely omitted. This was further tested with correlation testing for geographic context of altitude and bed slope.

For fish, a standardised protocol of biannual sampling has been in place for the last 8 years. A standard electrofishing protocol is carried out during low-flow periods (May-October) to collect information about fish assemblages in the monitoring network. The biotic index used in the evaluation of the ecological quality is the French fish-based index for the assessment of river health (IPR) (Oberdorff et al., 2002). The national fish-based multi-metric index IPR is composed of a set of seven metrics of taxonomic richness, abundance, habitat and trophic guilds and pollution sensitivity (see Table 3). Macro-invertebrate data is collected following the national protocol in summer with a Surber net sampler(Archaimbault et al., 2005). Taxa are identified at the genus level (except for Diptera and Oligochaeta for which the family level is used) and based on biological traits and abundances of taxa, the biological metrics are calculated for the sites. The French multi-metric index (I2M2) is composed of five metrics calculated at the reach level(Mondy et al., 2012) (see Table 3).Metrics both for fish as invertebrates are calculated based on the traits of the species for each site, based either on richness or abundance of taxons, measuring the deviation between the observed and the type-specific expected values. This reference-based approach gives for each trait-based metric a distance to reference condition for a site. Both for invertebrates and for fish the data of 2009 were selected from the database for each site. 
Table 3: Multi-metric indices for both macroinvertebrate and fish communities

\begin{tabular}{|c|c|c|c|}
\hline Community & $\begin{array}{l}\text { Multi-metric } \\
\text { Index }\end{array}$ & Metrics & metrics label \\
\hline \multirow{5}{*}{ Macro invertebrate } & \multirow{5}{*}{$\mathrm{I} 2 \mathrm{M} 2$} & $\begin{array}{l}\text { the relative abundance of multivoltine species in } \\
\text { the assemblage }\end{array}$ & Polyv. \\
\hline & & the relative abundance of ovoviviparous species & Ovov. \\
\hline & & Shannon diversity index & Shan. \\
\hline & & species tolerance in original ASPT & ASPT \\
\hline & & score a measure of taxonomic richness & TAX \\
\hline \multirow{7}{*}{ Fish } & \multirow{7}{*}{ IPR } & Taxonomic richness & NTE \\
\hline & & number of rheophilicspecies & NER \\
\hline & & number of lithophilic species & NEL \\
\hline & & Abundance of tolerant species & DIT \\
\hline & & Abundance of invertivorous species & DII \\
\hline & & Abundance of omnivorous species & DIO \\
\hline & & total fish abundance & DTI \\
\hline
\end{tabular}

\subsection{Statistical analysis}

Three successive statistical analyses were designed in order to distinguish upon the elements under question: whether the local or network impact of dam density prevails, whether functional metrics of the structure of the biotic communities explain more accurately the potential dam effects of community degradation, differentiate between impoundment habitat degradation and disconnection. First, a straightforward correlative analysis is performed where the bioticmetrics (see Table 2) are confronted with the damindicators (see Table 3) and hydromorphological stressor measures (see Table 1) using Spearman correlation testing.

Secondly, a multiple linear regression modeling (GLM) to determine the strength of the response between biotic indices and dam density measures at the local, regional and upstream catchment scale is performed. The first indications in the correlation analysis are used to select the metrics and predictors that we integrate in the GLM. Moreover, the GLM multiple regression enables to distinguish the variance explained by the different predictors at the different scale levels. Thirdly, as both the stressor and natural geographic context can influence the response,a residual analysis to show the interference of both environmental and community compositional factors to the dam response is performed. From the GLM multipleregressionfor the detected strongest explaining variables we will look in detail what factors of geography and hydromorphology are influencing this response, with a correlation analysis of the residuals for this regression.

\section{Results}

\subsection{Local and network dam impact}

Both for fish as for invertebrates significant relationships with local dam density are only present for specific trait-based metrics and not for the global biotic integrity indices (see Table 4). The integrated network measure of dam densityshows stronger correlations than the local dam density also both for fish as invertebrate metrics, indicating the accumulation of dam impact in the river network. For the network measures some significant responses are observed for the global indexes IPR and I2M2 as well.The dam density showed no specific spatial structure and so no spatial autocorrelation confounds 
these results. With correlation testing we found no relationship with altitude for dam density (R -0.04)

and only a minor correlation of density with bed slope (R 0.18 ).

For fish the strongest correlations are observed for the rheophilic species metric NER and the lithophilic species NEL. Both metrics correspond to the groups of (often migratory) species of free flowing river reaches. For the NER and NEL metrics the network impact shows the strongest responses. These responses are the same for slope weighed and non-weighed measures, and in the same order for network and local measures. For the density of omnivorous species DIO we observe a local dam density impact. The insectivorous species DII respond significantly to the non-weighed dam density in the local network. The species richness NTE on the contrary responds positive to network dam density.

For macro-invertebrates response is only present for slope weighed measures and gradually increasing from local to larger network measures of dam density, a strong response of the trait-based metrics of multivoltinism and ovoviviparity is observed. Shannon diversity shows a same response but less pronounced for the network, whereas the ASPT sensitive taxa only show a response to the network dam density.

Table 4: Spearman correlation values for the fish and invertebrate metrics and multi-metric indexwith the dam stressor indicators ( $\mathrm{N}=179$ for fish, $\mathrm{N}=211$ for macro-invertebrates). See Table 2 and 3 for variable labels.* Significant correlations $\mathrm{p}<0.05$.

\begin{tabular}{|c|c|c|c|c|c|c|c|c|c|}
\hline \multirow[b]{2}{*}{ Community } & \multirow[b]{2}{*}{ Metrics } & \multicolumn{4}{|c|}{ Local } & \multicolumn{3}{|c|}{ Regional network } & \multirow{2}{*}{$\begin{array}{l}\begin{array}{c}\text { Upstream } \\
\text { catchment }\end{array} \\
\text { Cumuld dam } \\
\end{array}$} \\
\hline & & dam\# & $\operatorname{dam}_{\mathrm{L}}$ & $\operatorname{dam\# }_{\mathrm{LS}}$ & NearDdam & $\begin{array}{c}\text { IIC_dam\#\# }_{\mathrm{L}} \\
\text { vois5 }\end{array}$ & $\begin{array}{c}\text { IIC_dam\# }_{\mathrm{LS}} \\
\text { vois5 }\end{array}$ & $\begin{array}{c}\text { IIC_dam\# }_{\text {LS }} \\
\text { vois10 }\end{array}$ & \\
\hline \multirow{7}{*}{ Fish } & IPR & $-0,08$ & $-0,12$ & $-0,14$ & 0,10 & $-0,19 *$ & $-0,21^{*}$ & $-0,15^{*}$ & $-0,11$ \\
\hline & NTE & 0,03 & 0 & 0,05 & 0,07 & 0,05 & $0,15^{*}$ & $0,15^{*}$ & $0,19 *$ \\
\hline & NER & $-0,12$ & $-0,16^{*}$ & $-0,21^{*}$ & 0,04 & $-0,26^{*}$ & $-0,26^{*}$ & $-0,24 *$ & $-0,22 *$ \\
\hline & NEL & $-0,11$ & $-0,15^{*}$ & $-0,2 *$ & 0,17 & $-0,24 *$ & $-0,29 *$ & $-0,27 *$ & $-0,27^{*}$ \\
\hline & DIT & 0,01 & 0 & 0,04 & 0,04 & 0,01 & 0,00 & 0,05 & 0,01 \\
\hline & DII & $-0,13$ & $-0,14$ & $-0,07$ & $-0,01$ & $-0,17^{*}$ & 0,10 & $-0,01$ & 0,07 \\
\hline & DIO & $-0,18^{*}$ & $-0,19 *$ & $-0,15^{*}$ & 0,03 & $-0,16^{*}$ & $-0,02$ & 0,07 & 0,05 \\
\hline \multirow{6}{*}{$\begin{array}{c}\text { Macro } \\
\text { invertebrate }\end{array}$} & I2M2 & 0,02 & $-0,01$ & $-0,09$ & 0,03 & $-0,01$ & $-0,28 *$ & $-0,37 *$ & $-0,38 *$ \\
\hline & Polyv. & 0,01 & 0,01 & $-0,15^{*}$ & 0,01 & 0,01 & $-0,40 *$ & $-0,43^{*}$ & $-0,45^{*}$ \\
\hline & Ovov. & $-0,02$ & $-0,02$ & $-0,19^{*}$ & 0,06 & $-0,02$ & $-0,37 *$ & $-0,50 *$ & $-0,60 *$ \\
\hline & Shan. & $-0,08$ & $-0,09$ & $-0,17 *$ & 0.07 & $-0,09$ & $-0,20 *$ & $-0,24 *$ & $-0,13$ \\
\hline & ASPT & 0,07 & 0,06 & $-0,04$ & 0,01 & 0,06 & $-0,25^{*}$ & $-0,38 *$ & $-0,38 *$ \\
\hline & TAX & 0,08 & 0,03 & 0,08 & $-0,02$ & 0,03 & 0,09 & 0,02 & 0,04 \\
\hline
\end{tabular}

\subsection{Disentangling disconnection and habitat degradation effect}

The respective weight of effects of disconnection and impoundment to overall dam impact can be discerned from the measured biological responses for the different predictor variables.

First, the difference in response to the slope weighed and non-weighed dam density measures (Ddam\# ${ }_{L S}$ and Ddam\# $_{L}$ respectively) can reveal impoundment impact. For fish the aspect of disconnection plays a major role, as both for the local and network context the non-weighed and 
weighed measures showed the same response. For macro-invertebrates the absence of a response to the

Second from specific indicators for habitat alteration: the alteration risk of bed substrate and structure and alteration risk to flow regime (hydrodynamics). Especially the trait-based metrics for fish showed different responses to the specific indicators for habitat alteration. The density of invertivorous (DII) and tolerant (DIT) species at the local scale only respond to hydrodynamics (Spearman R 0.29 and 0.19 respectively), whereas the density of omnivorous species (DIO) only responds to disconnection impact (same response to both dam density indicators). For the bed structure the rheophilic and lithophilic species metric responded the most significantly (NER: R 0.27 and NEL: R 0.31 ). NER and NEL respond strongly to both disconnectionand habitat degradation.

For the macro-invertebrates the trait-based metrics ofovoviviparityandmultivoltinism also show significant responses both to disconnection as local habitat degradation: for bed structure R -0.31 and 0.23 respectively, for hydrodynamics only the ovoviviparity correlates $\mathrm{R}-0.23$. At the local scale, habitat degradation effect dominates, whereas in general the contact with the upstream network is crucial and dominates strongly the community structure and diversity.

\subsection{Fish versus macro-invertebrate response}

The regression for the strongest explaining fish metrics of NER and NEL with the slope weighed dam density $\left(\operatorname{Ddam}_{L S}\right)$ at the three scale levels showed explained variances in the communities of 12 and $9 \%$. The integrated local network indicator (IIC, Fig. 3) was the strongest significant overall descriptor for this regression (Wilk's lambda 0.92, F 6.72, p 0.0015).

Yet, the partitioning of the explained variance showed that for the fish response, the explained fraction is much larger for local Ddam\# ${ }_{L S}(68 \%$ for NER and $61 \%$ for NEL), whereas the local network Ddam\# ${ }_{L S}$ explained respectively 25 and $33 \%$ for NER and NEL, and the upstream network Ddam\# ${ }_{L S}$ only accounts for less than $5 \%$ of the response (Fig. 4). 


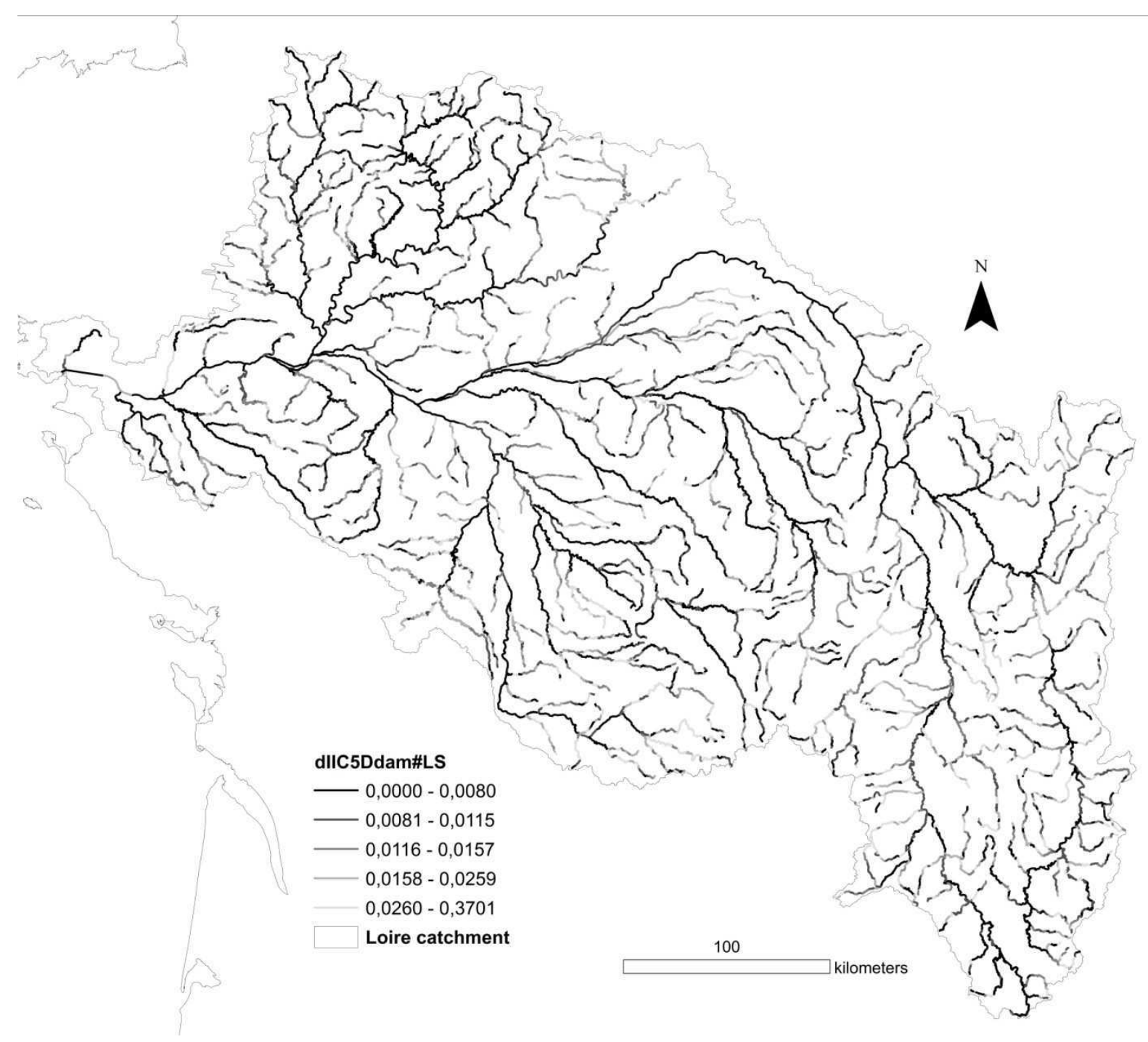

Figure 3.The dIICvalues of each Loire Basin river segment, calculated with topological distance 5 and slope weighed dam density $\left(\operatorname{Ddam\# }_{L S}\right)$, show the best connected local networks, least impacted by damming. Higher index values occur when local networks show low dam densities and high connectivity (river network branch density).

Stronger results are observed for invertebrate metrics, with a higher explained variance for the traitbased metrics of multivoltinism (19\%) and ovoviviparity (25\%) and here the upstream dam density (cumulu Ddam\# $\#_{L S}$ ) is by far the strongest significant descriptor (Wilk's lambda 0.99, F 47.29, p <0.0001). The $_{\text {cumulu }} D d a m \#_{L S}$ measure on its own explained $70 \%$ of the response to dam density and nearly $18 \%$ of the total variance observed for the macroinvertebrate trait-based metrics. 


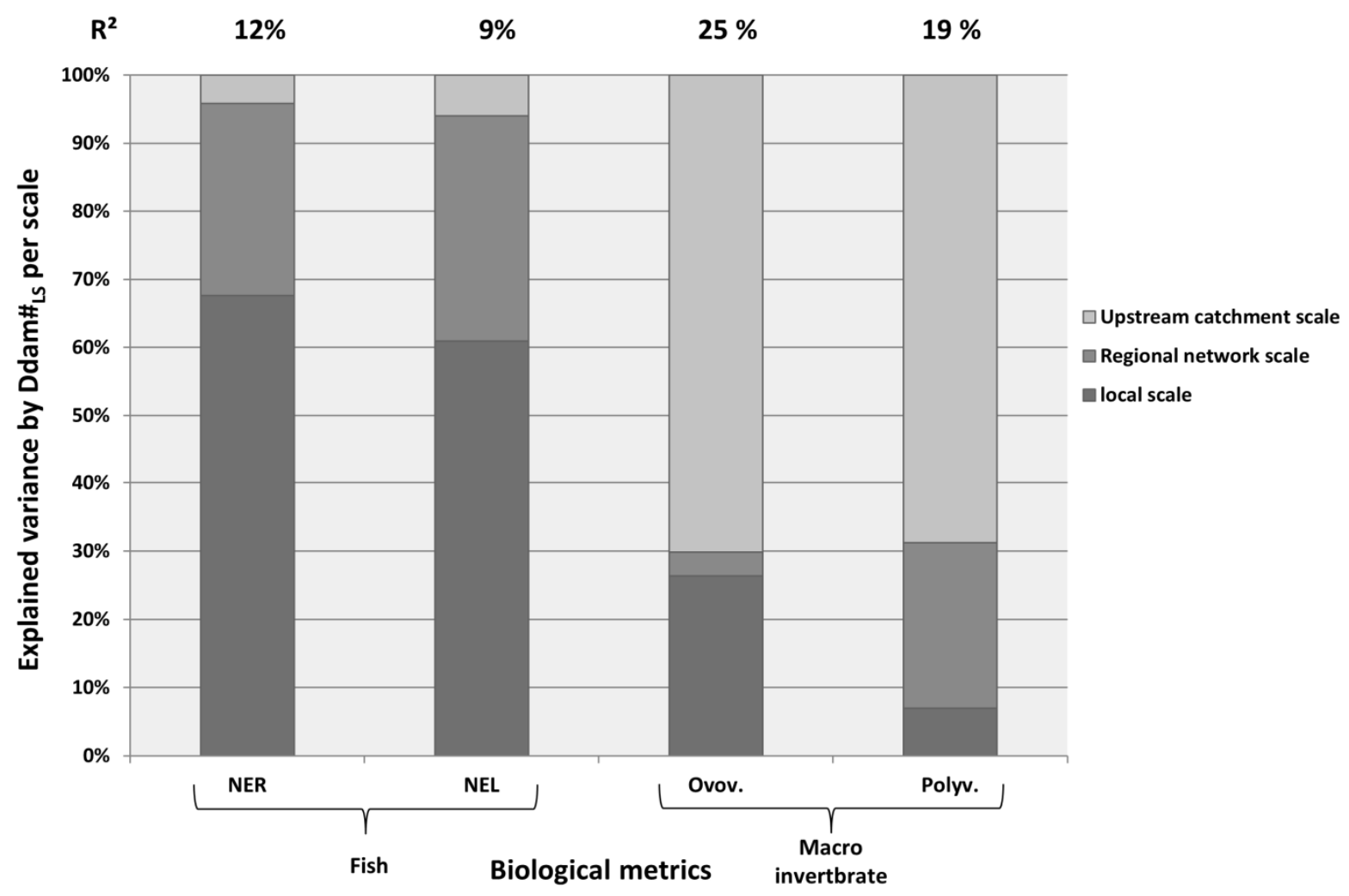

Figure 4. $\mathrm{R}^{2}$ and explained variance by the slope weighed dam density (Ddam\# ${ }_{\mathrm{LS}}$ ) per scale for NER and NEL fish metrics and ovoviviparity and multivoltinismmacroinvertebrate metrics from linear regression analyses. See Table 3 for metric labels.

\subsection{Upstream-downstream responses}

First observation for the correlations between the residuals and the geographic and geomorphic factors in Table 5 is that most of the fish residual responses are opposite to those for macro-invertebrates. For the fish-based metrics the only significant correlation between geographical variables and the residuals is present with the altitude $(\mathrm{R}-0.18)$. This negative relationship with altitude reveals that the fish community response is the clearest in higher parts of the river basin.Or put the other way: in the plains the fish communities respond less clearly to damming and impoundment, most probably due to confounding presence of many other stressors. The NEL metric shows high values for bed structure, indicating its strong response to local bed substrate and profile.

The residuals for the invertebrate response to dam density show a significant correlation to altitude, slope and naturalness of the catchment; but this time a positive correlation. The response of the invertebrate communities is less clear upstream than downstream. Multivoltinism and ovoviviparity only respond downstream. The response of multivoltinism and ovoviviparity is different with respect to river strahler order; negatively correlated for multivoltinism and positively for ovoviviparity.So, the response of the multivoltinism metric is more pronounced in the larger rivers. Ovoviviparity in contrast, shows a clearer response for the small lowland streams.

Table 5: Spearman correlation ranking between the geographical and geomorphological variables and the residuals of the regressions of the trait-based metrics with the the slope weighed dam density measure $\left(\right.$ Ddam $\left._{\mathrm{LS}}\right)$. See Table 1 and 3 for variable labels. 


\subsection{Strength of responses}

Where we observe significant relationships between the biologicalmetrics and dam density, nevertheless the presence of dams only explains a minor fraction of the variance observed for these metrics in our dataset. Reasons for this weak explicative power are in the first place the large scale data used in this analysis, with many sources of variance of both natural and human origin and a sampling that mostly avoided immediate dam influences, which hampers the investigation of direct causal relationships. Moreover, stations are retrieved from thenational monitoring network which is not designed to evaluate dam presence. For that purpose a specific set of sampling sites should be established, with the distinction of dam functionalities and characteristics of dam height and impounded section. Second confusing element to the detection of dam impact is the presence of multiple stressors in the river basin, with water pollution undoubtedly as main cause of injury.

Nevertheless these low values of explained variance $\left(\mathrm{R}^{2} \max \sim 12 \%\right.$ for fish and $25 \%$ for macroinvertebrates) for the stress response correspond to documented values for responses to alterations and human stressors in literature. In a similar analysis of Australian rivers based on macro-invertebrate data (Bush et al., 2012), a stronger response was detected downstream (with 5.3\% of the variance explained by human pressure) than upstream (with only $1.1 \%$ explained variance). The same values and conformity of macroinvertebrate response to human stressors restricted to the lower reaches was observed by Yuan (2010). Wang et al. (2011) show significant responses for both general biological integrity measures and for specific habitat indicators, with dam impact explaining $20 \%$ of the variance for the indicators in their data, as otherco-varying aspects were detected both linked to size, hydroregime and water quality stressors.

As in other studies of damming impact, no significant effect is evidenced in species diversity measures (Maynard and Lane, 2012). Yet, a significant decrease is observed for trait-based metrics that prove more relevant to identify specific stressors to aquatic communities (Brooks et al., 2011; Wooster et al., 2012; Vaughn 2012). Conform to the hypotheses, specific responses of the functional metrics to the spatially explicit dam density measures allow distinguishing impact scales and effects (habitat degradation and disconnection). Both the hypotheses find partly positive answers in these observed relationships: network impact proves more important than local habitat impacts for the invertebrate 
community, but not for the fish metrics. On the other hand disconnection impact prevails in fish response whereas habitat degradation dominates the macroinvertebrate response. The hypothesis of the scale-effect in disconnection impact with respect to mobility for respectively fish and invertebrates does not appear as straightforward in the observations.

\subsection{Impact in the network}

The overall community response is more significant to dam density measured at the regional scale level than for the individual reach. Our observationsarefor this aspect in agreement with the conclusion of Musil and colleagues for fish communities (Musil et al., 2012). In their analysis of 54 sites, fish biotic indices responded strongest to an integrated measure for dam density with respect to the distance to the site. In a similar study, Eros and colleagues showed that the larger the connected network without obstacles, the higher the conservation value for fish populations (Eros et al., 2011). Wang et al. (2011) concluded for fish population integrity to be influenced by the dam density downstream and upstream of a site. Here we observed this cumulative network impact for both fish and invertebrate communities and we go a step further even in explaining this network aspect by disentangling habitat degradation from connectivity aspects in the responses, and by linking specific responses to the geographic context of upstream-downstream and mountainous-lowland setting.

Where for fish no differentiation of the effect is observed between upstream and downstream accumulation (same response for IIC and upstream accumulation), for macroinvertebrates the strongest response was clearly for upstream dam density. Where Cumming (2004) observed the strongest impact on fish communities of downstream dam density and distance; here we observed neither for fish nor for macroinvertebrates a significant effect for distance to the nearest downstream dam. Yet, the absence of a fish response to the upstream basin context conforms to the statement of Cumming, that for fish connections are either locally in both directions, or for migratory species the downstream context is most relevant. As we did not distinguish the migratory species in our metrics, no specific response to downstream connectivity is observed.

\subsection{Specific responses of biotic communities}

First observation is that general taxonomic richness and diversity indices do not respond to dam density measures, neither for fish (NTE taxonomic richness and DTI taxonomic diversity), nor for invertebrates (Shannon diversity and taxonomic richness). Same counts for multi-metric biotic integrity indices, which are constructed to detect general degradations, yet are unable to identify specific stressors or pressure gradients. As significant relationships are only present for specific traitbased metrics and not for the global biotic integrity indices, this pleads for the application of specific metrics, more than the generalized multi-metric indices. As dam alterations can both result in increased metric values (f.i. for overall species number mostly) as degraded notes (for rheophilic species), the multi-metric indices do not respond consistently to the impairments associated with damming.

Based on these observed specific responses, selections ofmetric groups can be identified among the trait-based metrics for specific questions (detecting alterations, follow-up of restoration,...). For the expression of the local environment and habitat quality the trait-based metrics of NEL, DIT and DII can be considered, whereas for connectivity aspects the metrics DIO and NER are most susceptible to respond. The number of rheophilic species (NER) responds both to disconnection and local habitat degradation, and the number of lithophilic species (NEL) shows a response to disconnection as well. For macroinvertebrates the two trait-based metrics responded both to habitat degradation and disconnection.

Where all above discussed responses are general, the observed specific relationships to the geographic context are probably specific to the chosen dataset, and thus to the Loire River basin. A geographic differentiation was present in both groups. For the fish community the response is the clearest in the upstream parts of the basin. This geographic distinction is also observed in other fish studiesand 
accredited to a trade-off between contactand diversityand furthermore to the absence of interference with others stressors upstream(Hitt and Angermeier, 2008).

The macroinvertebrate communities reflect more clearly the dam impacts in the lower parts of the basin. For the downstream invertebrate communities more mass effects are at play, and the relationship with the perturbations is clearest for the abundances andespecially for the dominance ofeurytope,multivoltineand ovoviviparous species. The response of themultivoltinism metric is more pronounced in the larger rivers asthis trait ofmultivoltinismdetects best themass effects. Whereas the ovoviviparity in contrast shows a clearer response for the little lowland streams, as it is a metricthat is most sensible tohabitat degradation. This differentiation shows the conformity for these responses to findings for riverine ecosystem structuring (Brown and Swan, 2010) referring to the metacommunity mechanisms (Leibold et al., 2004), with downstream more mass effect relationships and regional forces dominating, whereas in more upstream parts community assemblage is more driven by species sorting mechanisms due to varying environmental conditions.

\subsection{Conclusions and recommendations}

Our analysis over the Loire Basin confirmsthat the impact of dams on the biotic communities is stronger at the regional than just at the local scale. With the functional trait metrics and the spatially explicit dam density measures the impact scales and effects of habitat degradation and disconnection could be discerned.

To management strategies and restoration options we can conclude that for upstream reaches the local habitat quality prevails and local restoration measures or dam removal can be successful. For downstream sections on the other hand, the presence of multiple stressors and the dominance of mass effects in biotic communities, imposes to look to the broader context and spatial scale. Restoration efforts will fail if we do not evaluate the need for contact between restoration site and regional pools, particularly for the restoration of communities that rely on the continual flux of individuals to and from regional dispersal pools like the invertebrates (Palmer et al., 1997, Spaenhoff and Arle, 2007). Local restoration efforts have moreover proven insufficient in lowland rivers with multiple stressors (Jaehnig et al., 2010; Stranko et al., 2012). So, for downstream sections focus must be on connectivity and more comprehensive approaches to restoration on larger watershed scales are needed.

\section{Acknowledgments}

The authors gratefully acknowledge the financial and structural support for the SYRAH hydromorphology audit project of the ministry of ecology, the water authorities and the French National Agency for Water and Aquatic Environments (ONEMA).

\section{Reference}

Acreman, M.C., Ferguson, A.J.D., 2010. Environmental flows and the European Water Framework Directive. Freshwater Biology 55, 32-48.

Archaimbault, V., Usseglio-Polatera, P.,Vanden Bossche, J.-P., 2005. Functional Differences Among Benthic Macroinvertebrate Communities in Reference Streams of Same Order in a Given Biogeographic Area. Hydrobiologia 551, 171-182.

Archaimbault, V., Usseglio-Polatera, P., Garric, J., Wasson, J.G., Babut, M., 2010 Assessing pollution of toxic sediment in streams using bio-ecological traits of benthic macroinvertebrates. Freshwater Biology 55, 1430-1446.

Benstead, J.P., March, J.G.,Pringle, C.M.,Scatena,F.N.,1999. The effects of a low-head dam and water abstraction on migratory tropical stream biota. Ecological Applications 9, 656-668. 
Blakely, T.J., Harding, J.S.,Mcintosh, A.R.,Winterbourn, M.J.,2006.Barriers to the recovery of aquatic insect communities in urban streams. Freshwater Biology 51, 1634-1645.

Brittain, J.E., Saltveit, S.J., 1989. A review of the effect of river regulation on mayflies (Ephemeroptera).Regulated Rivers: Research and Management 3, 191-204.

Brooks, A.J., Chessman, B.C., Haeusler, T., 2011.Macroinvertebrate traits distinguish unregulated rivers subject to water abstraction. Journal of the North American Benthological Society 30, 419-435.

Brown, B.L., Swan, C.M., 2010. Dendritic network structure constrains metacommunity properties in riverine ecosystems. Journal of Animal Ecology 79, 571-580.

Bush, A., Nipperess, D., Turak, E., Hughes, L., 2012. Determining vulnerability of stream communities to climate change at the landscape scale. Freshwater Biology 57, 1689-1701.

Chandesris, A., Mengin, N., Malavoi, J.R., Wasson, J.G., Souchon, Y., 2008. SYRAH-CE: SYstème Relationnel d'Audit de l'Hydromorphologie des Cours d'Eau A relational, multiscale system for auditing the hydro-morphology of running waters: diagnostic tool to help the WFD implementation in France. In: 4th international conference on river restoration, Venice, ITA, 16-21 June 2008. p. 4.

Chase, J.M., Leibold, M.A., 2002. Spatial scale dictates the productivity-biodiversity relationship. Nature 416, 427-430.

Conception, G.B., Nelson S.G., 1999. Effects of a dam and reservoir on the distribution and densities of macrofauna in tropical streams of Guam (Mariana Islands). Journal of Freshwater Ecology 14, 447-454.

Cortes, R.M.V., Ferreira, M.T.,Oliveira,S.V.,Godinho,F., 1998. Contrasting impacts of small dams on the macroinvertebrates of two Iberian mountain rivers. Hydrobiologia 389, 51-61.

Culp, J.M., Armanini, D.G., Dunbar, M.J., Orlofske, J.M., Poff, N.L., Pollard, A.I., Yates, A.G. \& Hose, G.C., 2011. Incorporating traits in aquatic biomonitoring to enhance causal diagnosis and prediction. Integrated Environmental Assessment and Management 7, 187-197.

Cumming, G.S., 2004. The impact of low-head dams on fish species richness in Wisconsin, USA. Ecological Applications 14, 1495-1506.

Eros, T., Schmera, D., Schick, R.S., 2011. Network thinking in riverscape conservation - A graph-based approach. Biological Conservation 144, 184-192.

Hansen, J.F. \& Hayes, D.B., 2012. Long-term implications of dam removal for macroinvertebrate communities in Michigan and Wisconsin rivers, United States. River Research and Applications, 28 1540-1550.

Hitt N.P., Angermeier P.L., 2008. River-stream connectivity affects fish bioassessment performance. Environmental Management 42, 132-150. 
Jaehnig, S.C., Brabec, K., Buffagni, A., Erba, S., Lorenz, A.W., Ofenboeck, T., Verdonschot, P.F.M., Hering, D., 2010. A comparative analysis of restoration measures and their effects on hydromorphology and benthic invertebrates in 26 central and southern European rivers. Journal of Applied Ecology 47, 671-680.

Lehner, B., Liermann, C.R., Revenga, C., Vorosmarty, C., Fekete, B., Crouzet, P., Doll, P., Endejan, M., Frenken, K., Magome, J., Nilsson, C., Robertson, J.C., Rodel, R., Sindorf, N., Wisser, D., 2011. High-resolution mapping of the world's reservoirs and dams for sustainable river-flow management. Frontiers in Ecology and the Environment 9, 494-502.

Leibold, M.A., Holyoak, M., Mouquet, N., Amarasekare, P., Chase, J.M., Hoopes, M.F., Holt, R.D., Shurin, J.B., Law, R., Tilman, D., Loreau, M., Gonzalez, A., 2004. The metacommunity concept: a framework for multi-scale community ecology. Ecology Letters 7, 601-613.

Lejon, A.G.C., Renöfält, M.B., Nilsson. C.,2009. Conflicts associated with dam removal in Sweden. Ecology and Society, 14(2), 4, 19 p.

Marchant, R.,Hehir, G., 2002. The use of AUSRIVAS predictive models to assess the response of lotic macroinvertebrates to dams in south-east Australia. Freshwater Biology 47, $1033-1050$.

Maynard, C.M. \& Lane, S.N. (2012) Reservoir compensation releases: impact on the macroinvertebrate community of the Derwent river, Northumberland, UK-A longitudinal study. River Research and Applications 28, 692-702.

Miller, S.W., Wooster, D., Li, J., 2007. Resistance and resilience of macroinvertebrates to irrigation water withdrawals. Freshwater Biology 52, 2494-2510.

Mondy, C.P., Villeneuve, B., Archaimbault, V., Usseglio-Polatera, P., 2012. A new macroinvertebrate-based multimetric index (I2M2) to evaluate ecological quality of French wadeable streams fulfilling the WFD demands: A taxonomical and trait approach. Ecological Indicators 18, 452-467.

Mouquet, N.,Loreau, M., 2002. Coexistence in metacommunities: the regional similarity hypothesis. Am. Nat. 159, 420-426.

Musil J., Horký P., Slavík O., Zbořil A., Horká P., 2012. The response of the young of the year fish to river obstacles: Functional and numerical linkages between dams, weirs, fish habitat guilds and biotic integrity across large spatial scale. Ecological Indicators 23, 634-640.

Nilsson, C., Reidy, C.A., Dynesius, M., Revenga, C., 2005. Fragmentation and Flow Regulation of the World's Large River Systems. Science 308, 405-408.

Oberdorff, T., Pont, D., Hugueny, B., Porcher, J.P., 2002. Development and validation of a fish-based index for the assessment of 'river health' in France. Freshwater Biology 47, 17201734.

Ormerod, S.J., Dobson, M., Hildrew, A.G., Townsend, C.R., 2010. Multiple stressors in freshwater ecosystems. Freshwater Biology 55, 1-4. 
684 Palmer, M.A., Ambrose, R.F., Poff, N.L., 1997. Ecological Theory and Community

685 Restoration Ecology. Restoration Ecology 5, 291-300.

686

687

688

689

690

691

692

693

694

695

696

697

698

699

700

701

702

703

704

Pascual-Hortal, L., Saura, S., 2006. Comparison and development of new graph-based landscape connectivity indices: towards the priorization of habitat patches and corridors for conservation. Landscape Ecol 21, 959-967.

Pascual-Hortal, L., Saura, S., 2008.Integrating landscape connectivity in broad-scale forest planning through a new graph-based habitat availability methodology: application to capercaillie (Tetraourogallus) in Catalonia (NE Spain). European Journal of Forest Research 127, 23-31.

Petts, G.E., 1984. Impounded rivers.John Wiley \& Sons, Chichester, United Kingdom.326 p.

Poff, N.L., Hart, D.D., 2002. How dams vary and why it matters for the emerging science of dam removal. Bioscience 52, 659-668.

Pohlon, E., Augspurger, C., Risse-Buhl, U., Arle, J., Willkomm, M., Halle, S.,Kusel, K., 2007. Querying the obvious: Lessons from a degraded stream. Restoration Ecology 15, 312316.

Poulet, N., 2007. Impact of weirs on fish communities in a Piedmont stream. River Research and Applications 23, 1038-1047.

Santucci, Jr. V.J., Gephard, S.R., Pescitelli, S.M., 2005. Effects of multiple low-head dams on fish, macroinvertebrates, habitat, and water quality in the Fox River, Illinois. North American Journal of Fisheries Management 25, 975-992.

Saura, S., Torné, J.,2009.ConeforSensinode 2.2: a software package for quantifying the importance of habitat patches for landscape connectivity.

Slawski, T.M., Veraldi, F.M., Pescitelli, S.M.,Pauers, M.J., 2008. Effects of tributary spatial position, urbanization, and multiple low-head dams on warmwater fish community structure in a Midwestern stream. North American Journal of Fisheries Management 28, 1020-1035.

Spaenhoff, B., Arle, J., 2007. Setting attainable goals of stream habitat restoration from a macroinvertebrate view. Restoration Ecology 15, 317-320.

Stranko, S.A., Hilderbrand, R.H., Palmer, M.A., 2012. Comparing the Fish and Benthic Macroinvertebrate Diversity of Restored Urban Streams to Reference Streams. Restoration Ecology 20, 747-755.

Tiemann, J.S., Gillette, D.P., Wildhaber, M.L.,Edds, D.R., 2004. Effects of lowhead dams on riffle-dwelling fishes and macroinvertebrates in a Midwestern river.Transactions of the American Fisheries Society. 133, 705-717.

Vaughn, C.C., 2012. Life history traits and abundance can predict local colonisation and extinction rates of freshwater mussels. Freshwater Biology 57, 982-992. 
733 Wang, L., Infante, D., Lyons, J., Stewart, J., Cooper, A., 2011. Effects of dams in river

734 networks on fish assemblages in non-impoundment sections of rivers in Michigan and

735 Wisconsin, USA. River Research and Applications 27, 473-487.

Watters, G. T., 1996.Small dams as barriers to freshwater mussels (Bivalvia, Unionidae) and their hosts. Biological Conservation 75, 79-85.

Wohl, E., 2012. Identifying and mitigating dam-induced declines in river health: Three case studies from the western United States. International Journal of Sediment Research, 27, 271287.

Wooster, D.E., Miller, S.W., Debano, S.J., 2012. An Examination of the Impact of Multiple Disturbances on a River System: taxonomic Metrics Versus Biological Traits. River Research and Applications 28,1630-1643. 
Author-produced version of the article published in Ecological Indicators (2014), vol. 37, p. 10-20 The original publication is available at http://www.sciencedirect.com, http://dx.doi.org/10.1016/j.ecolind.2013.10.006 